\title{
AMS RADIOCARBON DATING AND POLLEN ANALYSIS OF CORE KS0412-3 FROM KASHIBARU MARSH IN NORTHERN KYUSHU, SOUTHWEST JAPAN
}

\author{
Toshiyuki Fujiki ${ }^{1,2} \cdot$ Mitsuru Okuno $^{1,3}$ • Toshio Nakamura ${ }^{4}$ Shinji Nagaoka ${ }^{5}$ Yuichi Mori $^{6} \bullet$ \\ Kyoko Ueda ${ }^{7}$ Masahiko Konomatsu ${ }^{8}$ Jun Aizawa ${ }^{1,3}$
}

\begin{abstract}
We performed pollen analysis and accelerator mass spectrometry (AMS) radiocarbon dating on cored sediments (KS0412-3) from Kashibaru Marsh, located in the western part of the Sefuri Mountains in northern Kyushu, southwestern Japan, to investigate environmental change around the marsh. Sediment accumulation began in this marsh around cal AD 1200 and continued with an estimated average sedimentation rate of about $4 \mathrm{~mm} / \mathrm{yr}$. Human rice cultivation at this location began around cal AD 1300 and was abandoned due to the deposition of a thick sand layer at around cal AD 1400. Since this event, the area has been maintained as a "natural" marsh.
\end{abstract}

\section{INTRODUCTION}

Pollen analytical studies have been conducted in the lowland area of northern Kyushu, southwestern Japan, providing information to reconstruct past climate (Hatanaka 1978, 1985; Kuroda and Hatanaka 1979). Regarding the mountainous area, Okuno et al. (2001) reported micro- and macrofossils in landslide deposits (500 $\mathrm{m}$ asl) of the Sefuri Mountains and discussed the middle Holocene paleoenvironment. Unfortunately, the landslide deposits can provide only limited information for a short period. In contrast, marsh deposits are expected to preserve a continuous paleoenvironmental record. Therefore, Okuno et al. (2006, 2011) studied sediments in Kashibaru (also known as Kashinokibaru) Marsh (Figure 1) extracted with a hand auger sampler and with an estimated basal dating of about cal AD 1200.

Pollen analysis is a useful tool for revealing the dynamics of plant communities. Poaceae pollen grains are important because an increase in their relative abundance implies a decrease in forest density. The appearance of the fossil pollen of rice (a Poaceae species) is considered to be a major indicator for the beginning of rice cultivation. Poaceae pollen grains have a relatively simple morphology consisting of a spheroidal shape with a single pore (monoporate type). Although Poaceae pollen is easily identifiable at the family level, it is often difficult to identify at the genus or species level with a light microscope. Nakamura (1974) conducted a study of the fine surface structure of 68 species of Poaceae pollen distributed throughout Japan with a transmission electron microscope using a "replica method" and recognized 3 characteristics of Poaceae pollen ornamentation.

To provide key elements to reconstruct the past environment in Kyushu, we reconstructed paleoenvironmental and land-use changes in and around the Kashibaru Marsh using pollen analysis as well

\footnotetext{
${ }^{1}$ AIG Collaborative Research Institute for International Study on Eruptive History and Informatics (ACRIFIS-EHAI), Fukuoka University, 8-19-1, Nanakuma, Jonan-ku, Fukuoka 814-0180, Japan.

${ }^{2}$ Corresponding author. Email: tengmu104@yahoo.co.jp.

${ }^{3}$ Department of Earth System Science, Faculty of Science, Fukuoka University, 8-19-1 Nanakuma, Jonan-ku, Fukuoka 8140180, Japan.

${ }^{4}$ Center for Chronological Research, Nagoya University, Furo-cho, Chikusa-ku, Nagoya 464-8602, Japan.

${ }^{5}$ Formerly Department of Geography, Faculty of Education, Nagasaki University, 1-14 Bunkyo-machi, Nagasaki 852-8521, Japan. Deceased July 2011.

${ }^{6}$ Department of Pharmacy, Kinjo Gakuin University, 2-1723 Omori, Moriyama-ku, Nagoya 496-0004, Japan.

${ }^{7}$ Aich Prefectural Meiwa High School, 2-32-6 Shirakabe, Higashi-ku, Nagoya 461-0011, Japan.

${ }^{8}$ Department of Earth Science, Faculty of Education, Wakayama University, 930 Sakaedani, Wakayama 640-8510, Japan.
}

(C) 2013 by the Arizona Board of Regents on behalf of the University of Arizona

Proceedings of the 21st International Radiocarbon Conference edited by A J T Jull \& C Hatté

RADIOCARBON, Vol 55, Nr 2-3, 2013, p 1693-1701 


\section{T Fujiki et al.}

as accelerator mass spectrometry (AMS) radiocarbon dating of the cored samples. Furthermore, to identify the cultivation type of Poaceae and to demonstrate evidence of the previous existence of a paddy field in this area, we also determined the surface type of the fossil Poaceae pollen with a scanning electron microscope (SEM) based on the characteristics described by Nakamura (1974).

\section{SAMPLES AND ANALYTICAL METHODS}

\section{Geological Settlement}

Kashibaru Marsh (591 m asl) is located in the western part of the Sefuri Mountains in northern Kyushu, southwestern Japan (Figure 1). The mountains consist of Cretaceous plutonic rock with a roof pendant of Sangun metamorphic rock (Karakida et al. 1992).

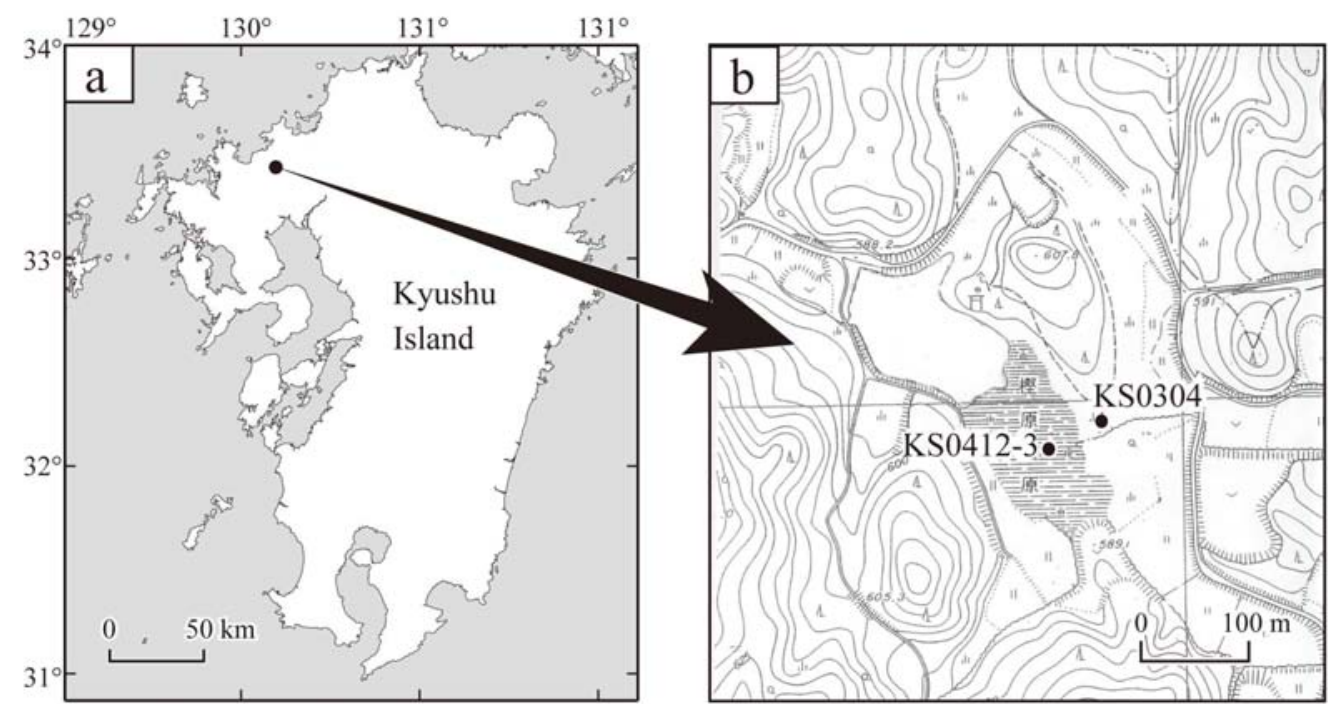

Figure 1 (a) Index map showing the location of the Sefuri Mountains on Kyushu Island. (b) Locations of the coring sites (KS0412-3 and KS0304) in Kashibaru Marsh.

\section{Location of the Drilling Site}

Whereas Okuno et al. $(2006,2011)$ studied sediments in core KS0304 obtained by a hand auger sampler, we collected core samples (KS0412-3) from the bottom to the top of the marsh deposits in December 2004 using a drilling machine. Core KS0412-3 was taken in the central part of the marsh, where the thickest deposits were expected (Figure 1; $33^{\circ} 24^{\prime} 54^{\prime \prime} \mathrm{N}, 130^{\circ} 9^{\prime} 26^{\prime \prime} \mathrm{E}$ ). About 90 species of native plants were recognized in the marsh, including Scirpus nipponicus, Utricularia multispinosa, and Menyanthes trifoliata (Iwamura and Kuranari 1972). The surrounding vegetation is a secondary forest of Pinus densiflora and plantations of Japanese cedar (Cryptomeria japonica). The average annual rainfall in this area is about $2500 \mathrm{~mm}$ (Ando and Yoshimori 2007), with a mean annual temperature of about $13^{\circ} \mathrm{C}$ (Iwamura and Kuranari 1972).

\section{Stratigraphy}

The $400-\mathrm{cm} \mathrm{KS0412-3} \mathrm{core} \mathrm{was} \mathrm{retrieved} \mathrm{in} \mathrm{100-cm} \mathrm{intervals} \mathrm{(86} \mathrm{mm} \mathrm{in} \mathrm{diameter).} \mathrm{The} \mathrm{stratigra-}$ phy of the core samples is shown in Figure 2. The cored sediments can be divided into 4 facies: i.e. silt (400-377, 348-313, 300-227, 200-159, 141-89, 64-21, and $10 \mathrm{~cm}$ to surface); sandy silt (377- 
$348 \mathrm{~cm}$ ); fine sand (227-219 cm); and medium to coarse sand (313-300, 219-200, 159-141, 89-64, and $21-10 \mathrm{~cm}$ ). Sand grains appear to have been derived from nearby granite badlands around the marsh as a debris flow. No tephra layer was recognized within this core.

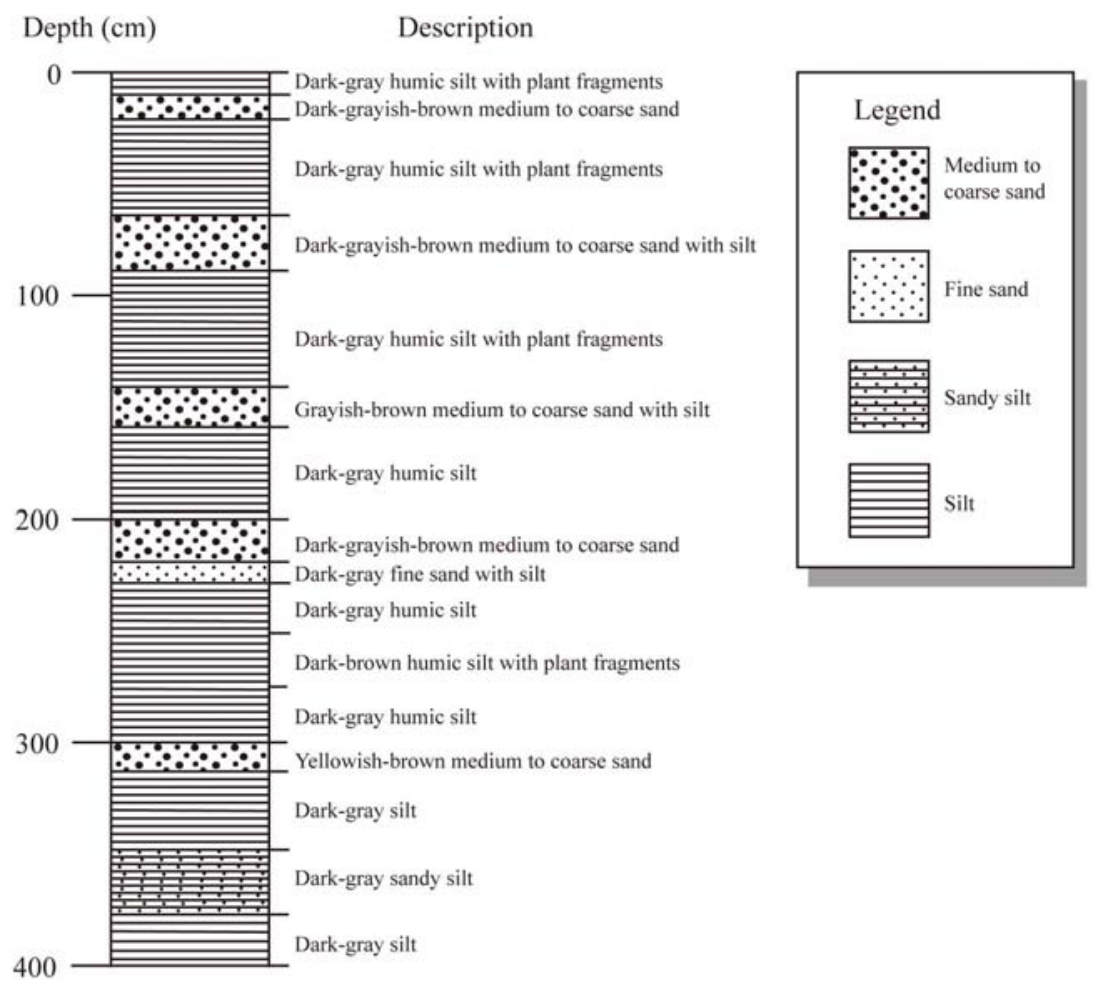

Figure 2 Columnar section showing the stratigraphy of the KS0412-3 core

\section{AMS Radiocarbon Dating}

The plant fragments were collected from 3 horizons immediately after coring. Unfortunately, suitable samples for ${ }^{14} \mathrm{C}$ dating were limited in these horizons. In addition, we could not identify plant species or parts. Samples were purified by routine acid-alkali-acid (AAA) treatments using $1.2 \mathrm{~N} \mathrm{HCl}$ and $1.2 \mathrm{~N} \mathrm{NaOH}$, respectively, followed by washing with distilled water and drying. Each purified sample was sealed in a quartz tube together with $\mathrm{CuO}$ and then heated to $850{ }^{\circ} \mathrm{C}$ for $4 \mathrm{hr}$. The produced gas was cryogenically purified to $\mathrm{CO}_{2}$ gas using a vacuum line, and then reduced catalytically to graphite on Fe powder with $\mathrm{H}_{2}$ gas (Kitagawa et al. 1993). Prepared samples were measured by the HVEE Tandetron AMS system (model 4130-AMS) at Nagoya University (Nakamura et al. 2000). All 3 carbon isotopes in both the samples and the NIST oxalic acid (HOxII) standard were measured with the AMS system. The ${ }^{13} \mathrm{C} /{ }^{12} \mathrm{C}$ ratios $\left({ }^{13} \mathrm{C}_{\mathrm{PDB}}\right)$ obtained by the AMS system were used to correct carbon isotopic fractionation when calculating conventional ${ }^{14} \mathrm{C}$ ages. The ${ }^{14} \mathrm{C}$ age errors were estimated by machine errors evaluated by the ${ }^{14} \mathrm{C}$ reproducibility of repeated measurements on standard targets and errors in ${ }^{14} \mathrm{C}$ background removal calculations (Nakamura et al. 2007). 
T Fujiki et al.

\section{Pollen Analysis}

A few grams of sample were collected from the core every $5 \mathrm{~cm}$ for pollen analysis. Fossil pollen and spores were extracted by $10 \% \mathrm{KOH}$ treatment, $\mathrm{ZnCl}_{2}$ solution treatment, and Erdtman's acetolysis method (Erdtman 1934). To determine pollen assemblages, samples were dehydrated with an ethanol series (30\%, 60\%, and 99.5\%) and then treated with xylene after acetolysis. The samples were mounted in Eukitt for observation under a light microscope. Five hundred or more pollen grains (excluding spores) were counted, including at least 300 arboreal pollen grains, in each sample. The percentage of each taxon (arboreal and non-arboreal pollen, and fern spores) was based on the total arboreal pollen count.

To observe the morphology of the fossil Poaceae pollen by SEM, a sample from $348 \mathrm{~cm}$ depth was fixed and treated for conductive coating with $2 \%$ osmium tetroxide solution after acetolysis, dehydrated with an ethanol series, then treated with xylene. The sample was set on stands and spattered with gold-palladium for $\sim 5$ min. The JSM-6300 SEM by JEOL Ltd., Japan was used for observation.

\section{RESULTS AND DISCUSSION}

\section{Depositional Age}

The results of AMS ${ }^{14} \mathrm{C}$ dating are shown in Table 1 and Figure 3. Since the Sefuri Mountains consist of plutonic and metamorphic rocks containing no carbonaceous material, a hardwater effect on water plants grown in the marsh could be small, even though degradation of old organic matter contained in the sediments in and around the marsh may produce a certain degree of hardwater effect. The marsh is located more than $50 \mathrm{~km}$ from active volcanoes existing in northern Kyushu; thus, the effect of volcanic $\mathrm{CO}_{2}$ depleted in ${ }^{14} \mathrm{C}$ on the photosynthesis of plants and trees around the marsh is negligible. Thus, the calibration of the obtained ${ }^{14} \mathrm{C}$ dates we assume a constant reservoir age along the sequence and equal to 0 . It is noteworthy that the obtained ${ }^{14} \mathrm{C}$ dates do not show any inversion, and this corroborates that our assumption of constant and even zero reservoir age is not misleading.

Table 1 Results of AMS ${ }^{14} \mathrm{C}$ dating.

\begin{tabular}{|c|c|c|c|c|}
\hline $\begin{array}{l}\text { Depth } \\
\text { (cm) }\end{array}$ & $\begin{array}{l}\delta^{13} \mathrm{C}_{\mathrm{PDB}} \\
\text { (\%) }\end{array}$ & $\begin{array}{l}{ }^{14} \mathrm{C} \text { date } \\
\text { (BP) }\end{array}$ & $\begin{array}{l}\text { Lab nr } \\
\text { (NUTA2-) }\end{array}$ & $\begin{array}{l}\text { Age range (cal AD) } \\
(2 \sigma \text {, probability \%) }\end{array}$ \\
\hline 51 & -29.0 & $110 \pm 25$ & 8622 & $\begin{array}{cc}1682-1736 & (28.6 \%) \\
1804-1935 & (70.7 \%) \\
1951-1954 & (0.07 \%)\end{array}$ \\
\hline 278 & -28.5 & $390 \pm 25$ & 8621 & $\begin{array}{cc}1442-1522 & (79.3 \%) \\
1574-1584 & (1.6 \%) \\
1590-1624 & (19.2 \%)\end{array}$ \\
\hline 375 & -30.2 & $795 \pm 25$ & 8620 & $1209-1276(100 \%)$ \\
\hline
\end{tabular}

${ }^{14} \mathrm{C}$ dates were calibrated to calendar age ranges with the IntCal09 data set (Reimer et al. 2009) using the CALIB v 6.0 software (Stuiver and Reimer 1993; Stuiver et al. 2010). Although the calibrated age spanned a wide range ( $\sim 70$ to $270 \mathrm{yr}$ with $2 \sigma$ probability), the sedimentation rate of the marsh deposits was estimated to be $\sim 4 \mathrm{~mm} / \mathrm{yr}$ based on modal points of the lower 2 dates. Because sand layers can be deposited rapidly by debris flows, these layers can be disregarded when estimating the sedimentation rate. The result indicates that the marsh deposits have accumulated since about cal AD 1200. This age is similar to a previous age obtained from the KS0304 core. In addition, as discussed below, human rice cultivation existed here around cal AD 1300, according to the obtained ${ }^{14} \mathrm{C}$ dates. This age is consistent with the global Medieval Warm Period (10th-14th century). 
AMS ${ }^{14} C$ Dating and Pollen Analysis, Kashibaru Marsh

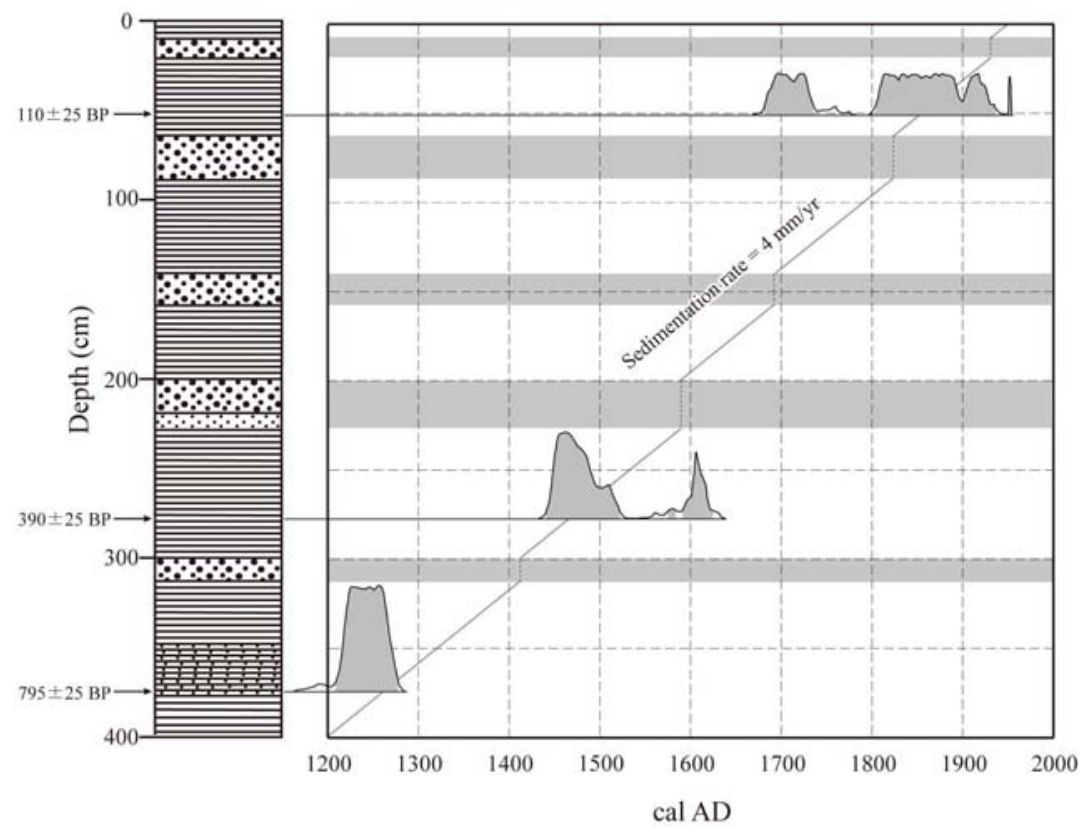

Figure 3 Histogram of the probability distribution for calibrated ${ }^{14} \mathrm{C}$ dates of the plant fragments from the KS0412-3 core. Sandy horizons are shown by shading.

\section{Pollen Assemblages}

The analyzed pollen data are plotted in Figures 4 and 5. Trends in the appearance of the main pollen types are as follows. The occurrence of Pinus pollen of the secondary forestelement was very low below $370 \mathrm{~cm}$ depth but suddenly increased to $50 \%$ to $80 \%$ above $200 \mathrm{~cm}$. Carpinus and Betula pollen grains of the cool temperate deciduous broad-leaved forest element were abundant below $200 \mathrm{~cm}$. Quercus subgenus Lepidobalanus pollen of the cool temperate deciduous broad-leaved forest element comprised $<10 \%$ of pollen throughout all layers. Quercus subgenus Cyclobalanopsis pollen of the warm temperate evergreen broad-leaved forest element was dominant below $350 \mathrm{~cm}$, exhibiting high percentages ranging from $50 \%$ to $90 \%$. However, this pollen decreased to $<10 \%$ of pollen content below $100 \mathrm{~cm}$ (Figure 4). Herb pollen grains such as Poaceae, Cyperaceae, Haloragis, and Artemisia dominated from 350 to $150 \mathrm{~cm}$ (Figure 5). No evidence of human impact on the natural vegetation was observed in the lowest part of the core, where pollen of a potential natural vegetation element, Quercus subgenus Cyclobalanopsis, dominated. Quercus subgenus Cyclobalanopsis pollen rapidly decreased, whereas secondary forest elements such as Pinus (e.g. P. densiflora) pollen showed a rapid increase, indicating a more pronounced human impact on natural vegetation. Japanese cedar was introduced around this marsh $\sim 200 \mathrm{yr}$ ago, as reflected in the increase in Cryptomeria japonica pollen in the upper part of the core. Poaceae pollen increased from 360 to $320 \mathrm{~cm}$, and the pollen of lowland weed elements such as Sagittaria and Alisma increased slightly at the same time. It is quite possible that rice (Poaceae) was cultivated at this site. Fagopyrum pollen was also detected in the core sample and increased slightly from 240 to $160 \mathrm{~cm}$. It is likely that buckwheat was also cultivated at this site. Pollen grains of swamp elements, including Typha and Lythrum, increased from about $250 \mathrm{~cm}$. This finding indicates that the wetland environment regained its natural vegetation and that rice cultivation never occurred again at this site. 
T Fujiki et al.

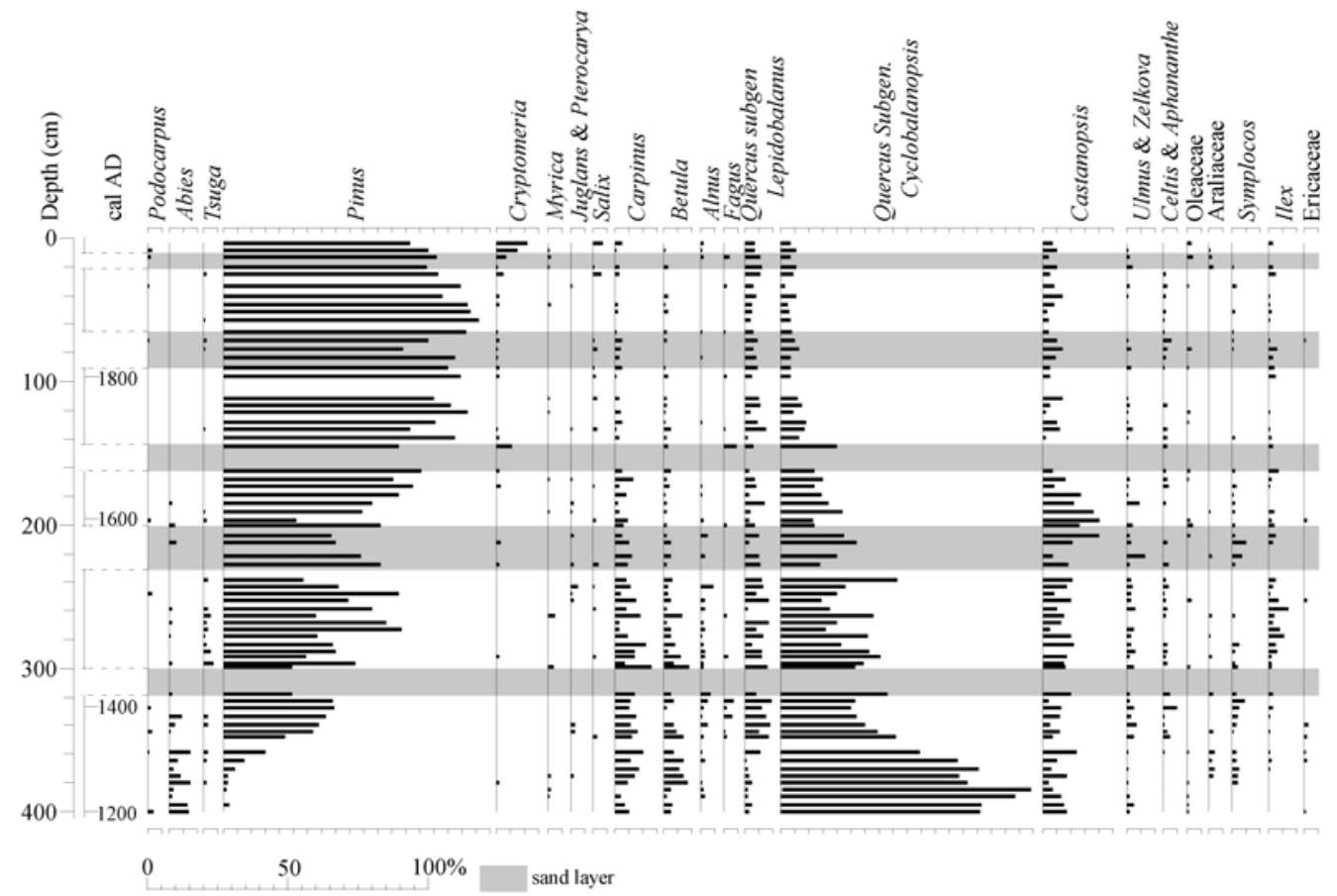

Figure 4 Arboreal pollen diagram for the KS0412-3 core

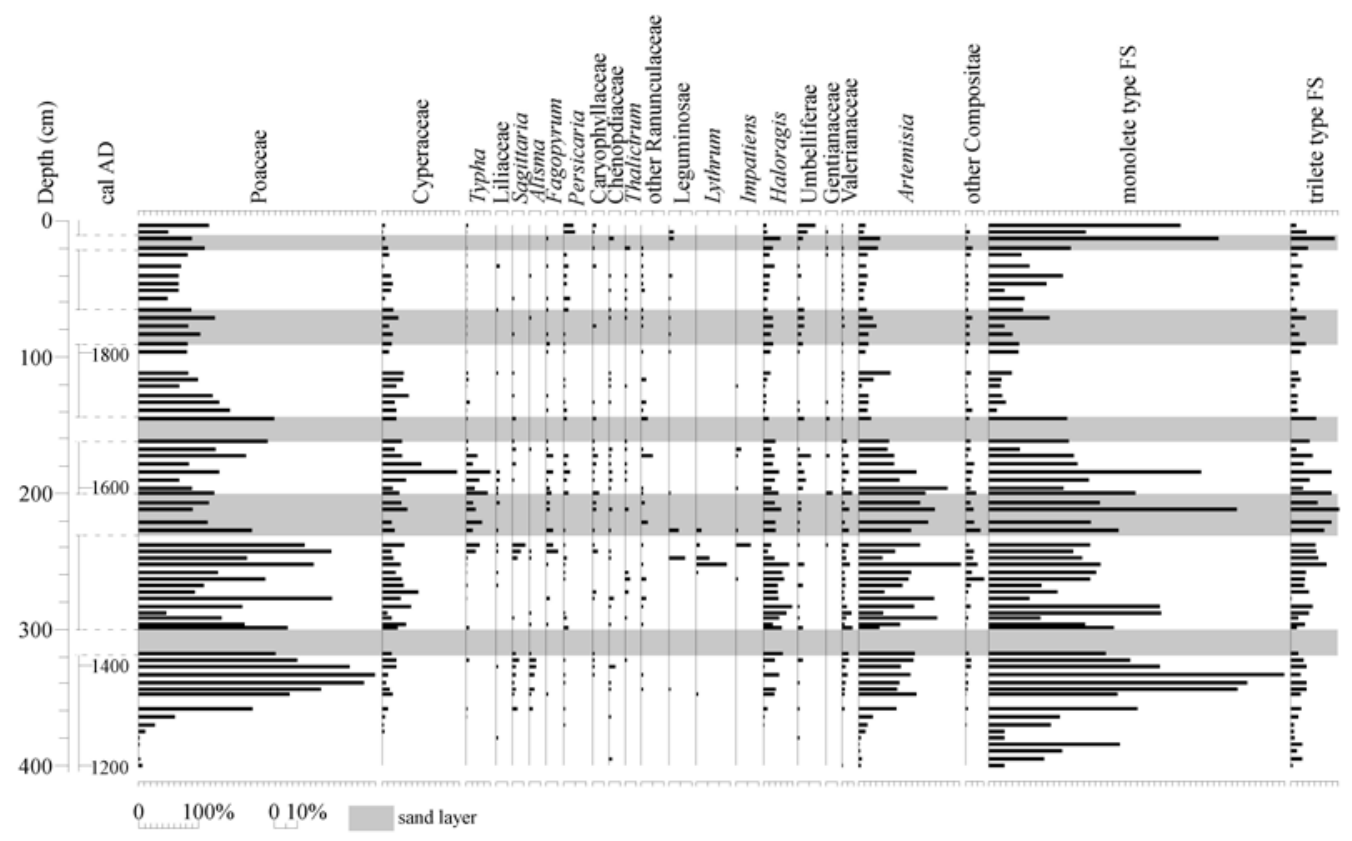

Figure 5 Non-arboreal pollen diagram for the KS0412-3 core 
AMS ${ }^{14} C$ Dating and Pollen Analysis, Kashibaru Marsh
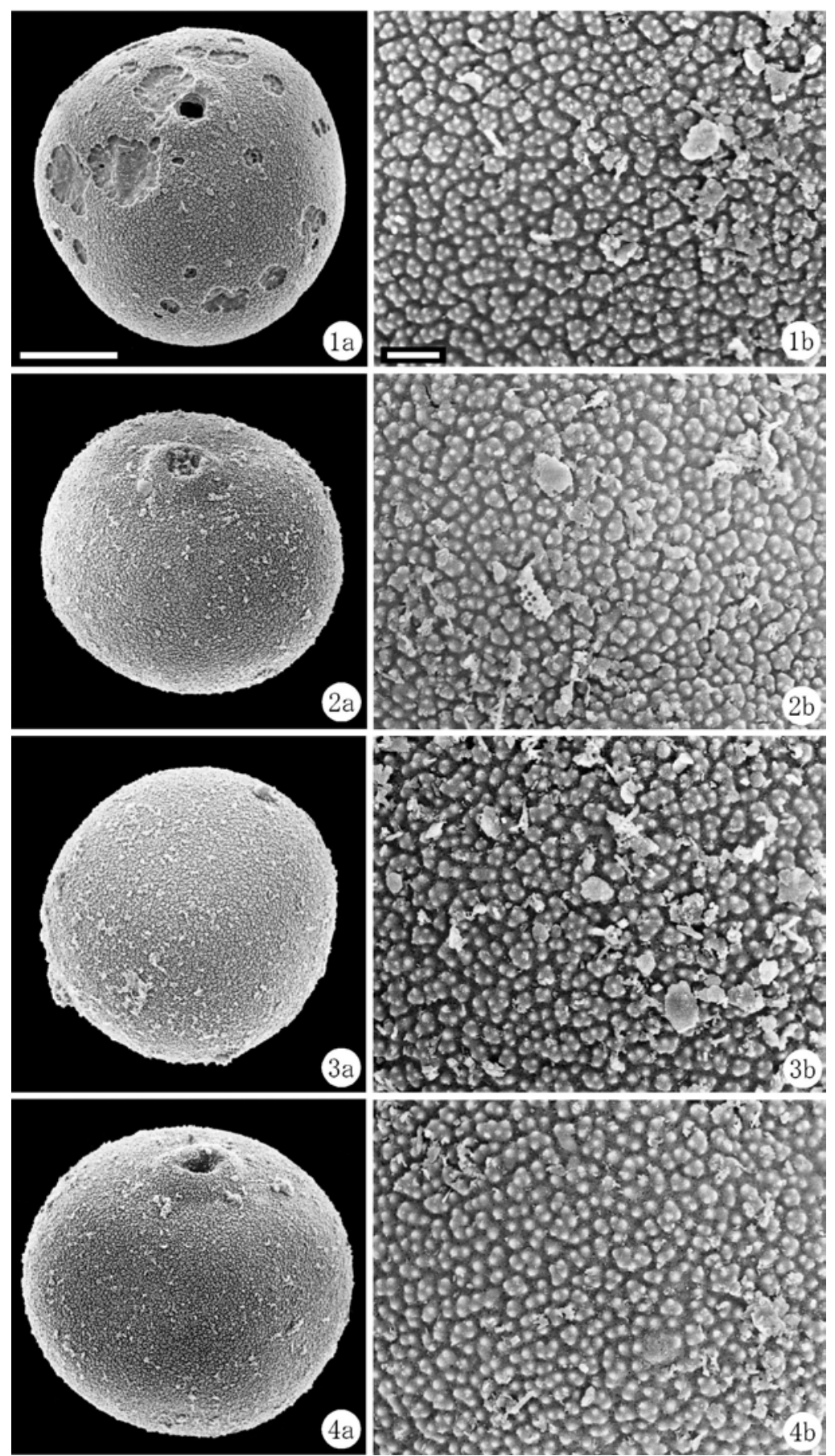

Figure 6 Selected SEM microphotographs of the fossil Poaceae pollen found at $348 \mathrm{~cm}$ depth in the KS0412-3 core. Scale bars are (a) $10 \mu \mathrm{m}$ and (b) $1 \mu \mathrm{m}$. Photograph 1 is type III, and other specimens are type II, the cultivated type. 


\section{T Fujiki et al.}

These data indicate that humans used the site and surrounding area as a rice field, and rice cultivation is considered to have started around cal AD 1300. The marsh was subsequently buried by a medium to coarse sand layer at cal AD 1400, after which time the paddy field was abandoned. The marsh has been preserved since its burial in about cal AD 1400. Although the wetland recovered sufficiently to be used again for rice cultivation, this has not occurred. This result is consistent with insect and diatom assemblages in the KS0304 core (Okuno et al. 2006, 2011). According to Okuno et al. (2011), index diatoms for the paddy field, such as Rhopalodia gibberula, Aulacoseira ambigua, and Navicula elginensis, appeared at a high rate below $300 \mathrm{~cm}$ (corresponding to about cal AD 1350-1550), and remains of the rice pest Donacia provostii also appeared. These diatoms inhabit current paddy fields (Mori 1999, 2002). Many remains of $D$. provostii have been discovered in the soil layers of paddy fields since the early Yayoi period ( 500 cal BC) in Japan (Mori 1996, 2002). These diatoms and insects are indicative of a paddy field layer in this marsh (Okuno et al. 2011). In contrast, none of these indicators were present above $300 \mathrm{~cm}$ in the KS0304 core. Instead, taxa such as Plateumaris sericea, which inhabit shallow wetlands, and Donacia clavareaui, which inhabit the sedge community of wetlands with less open water, appeared in high abundance. Therefore, data from the KS0304 core suggest that rice cultivation was abandoned around cal AD 1400. The results of the pollen analysis conducted in this study are consistent with those of the diatom and insect analyses of the KS0304 core.

\section{Morphology of Fossil Poaceae Pollen}

The ornamentations of Poaceae pollen grains are divided into the following 3 types: type I is composed only of microgranules; type II is a mixture of microgranules and insulae; and type III is composed only of insulae (Nakamura 1974). The fine surface structures of pollen grains of cultivated Poaceae (rice) are often of type II. The fine surface structures of fossil rice pollen grains from 348 $\mathrm{cm}$ depth are shown in Figure 6. These grains were analyzed following the classification of Nakamura (1974) and showed a high amount of type II ornamentation, suggesting that many fossil rice pollen grains were from cultivated rice. The presence of such fossil pollen grains strongly indicates that rice was cultivated.

\section{CONCLUSIONS}

Pollen analysis and AMS ${ }^{14} \mathrm{C}$ dates revealed the origin of Kashibaru Marsh and subsequent environmental changes in the marsh. Sediment accumulation in this marsh started around cal AD 1200. The marsh was used as a rice field as early as cal AD 1300 and was subsequently buried by a medium to coarse sand layer around cal AD 1400. Cultivation was abandoned as a result of a geological hazard, as evidenced by the sand layers deposited by a debris flow. Since the burial of the rice field, the marsh has remained in a "natural” state.

\section{ACKNOWLEDGMENTS}

We would like to thank Dr Kiyofumi Yoshimori of the Saga Prefectural Government for granting permission to core at the Kashibaru Marsh. We also thank Dr Kazuyuki Matsusue of OYO Corporation for his support and assistance with core sample collection. The authors are very grateful to anonymous reviewers, the editors, and Dr Ma Hannah T Mirabueno for their detailed and constructive comments and suggestions that helped to improve our paper. This work was partly supported by a Grant-in-Aid (14380031 and 15068206, 21101002) for Scientific Research from the Japan Society for the Promotion of Science (JSPS) and the Ministry of Education, Culture, Sports, Science and Technology (MEXT), Japan. 


\section{REFERENCES}

Ando K, Yoshimori K. 2007. Natural reproduction in the Kashibaru Marshland. Soil Mechanics and Foundation Engineering (Tsuchi-to-Kiso) 55(7):12-6. In Japanese with English abstract.

Erdtman G. 1934. Über die verwendund von essigsäureanhydrid bei pollenuntersuchungen. Svenska Botanica Tiddskrift 28:354-61.

Hatanaka K. 1978. Pollen analytical studies on the vegetational history since the late-glacial age in Kyushu, Japan (1). Journal of the Faculty of Literature, Kitakyushu University (Series B) 10:1-12.

Hatanaka K. 1985. Palynological studies on the vegetational succession since the Würm Glacial Age in Kyushu and adjacent areas. Journal of Faculty of Literature, Kitakyushu University (Series B) 18:29-71.

Iwamura M, Kuranari Y. 1972. Kashibaru marsh: wetlands in saga (6). Plants in Saga (Saga-no-Shokubutu) 6-7:18-23. In Japanese.

Karakida Y, Hayasaka S, Hase Y, editors. 1992. Regional Geology of Japan, Part 9. Kyushu. Tokyo: Kyoritsu Shuppan Co., Ltd. In Japanese.

Kitagawa H, Masuzawa T, Nakamura T, Matsumoto E. 1993. A batch reparation method for graphite targets with low background for AMS ${ }^{14} \mathrm{C}$ measurements. Radiocarbon 35(2):295-300.

Kuroda T, Hatanaka K. 1979. Palynological study of the Late Quaternary in the coastal plain along Hakata Bay in Fukuoka City, Northern Kyushu, Japan. The Quaternary Research (Daiyonki-Kenkyu) 18:53-68.

Mori Y. 1996. The insect fossils and rice cultivation in Japan. Archaeology Quarterly (Kikan-Kokogaku) 56: 59-63. In Japanese.

Mori Y. 1999. Fossil diatom assemblages from pre-historical and historical deposits and their paleoenvironmental applications. Diatom (Journal of the Japanese Society of Diatomology) 15:127-47. In Japanese with English abstract.

Mori Y. 2002. The origin and development of rice paddy cultivation in Japan based on evidence from insect and diatom fossils. In: Yasuda Y, editor. The Origins of Pottery and Agriculture, New Delhi: Roli Books Pvt. Ltd. and Lustre Press Pvt. Ltd. p 273-96.

Nakamura J. 1974. Some palynological notes on grass pollen, with special reference to Oryza sativa. The Quaternary Research (Daiyonki-Kenkyu) 13:187-98.
In Japanese with English abstract.

Nakamura T, Niu E, Oda H, Ikeda A, Minami M, Takahashi H, Adachi M, Pals L, Gottdang A, Suya N. 2000. The HVEE Tandetron AMS system at Nagoya University. Nuclear Instruments and Methods in Physics Research B 172(1-4):52-7.

Nakamura T, Okuno M, Kimura K, Mitsutani T, Moriwaki H, Ishizuka Y, Kim KH, Jing BL, Oda H, Minami M, Takada H. 2007. Application of ${ }^{14} \mathrm{C}$ wiggle-matching to support dendrochronological analysis in Japan. Tree-Ring Research 63(1):37-46.

Okuno M, Nagaoka S, Hase Y, Mori Y, Konomatsu M, Takahashi T, Nakamura T, Nishida T. 2001. 5.2-5.8 ka BP paleo-environment of the southern slope of Mount Raizan, Japan. Radiocarbon 43(2B):703-10.

Okuno M, Mori Y, Ueda K, Nakamura T, Nagaoka S, Aizawa J, Fujiki T, Konomatsu M, Inenaga K, Mizuta T. 2006. Physical properties and radiocarbon age of the KS0304 core from the Kashinokibaru Marsh in northern Kyushu, SW Japan. Fukuoka University Science Reports 36(1):31-41. In Japanese with English abstract.

Okuno M, Mori Y, Fujiki T, Sugiyama S, Konomatsu M, Ueda K, Nagaoka S, Nakamura T, Aizawa J. 2011. Human activity and sediment disaster in medieval period at the Kashibaru Marsh, Sefuri Mountains in the northern part of Kyushu Island, Japan. In: Nakajo T, Sakai H, Ishida H, editors. Science of Archaeology, Kyoto: Rinsen Book Co. p 79-98. In Japanese.

Reimer PJ, Baillie MGL, Bard E, Bayliss A, Beck JW, Blackwell PG, Bronk Ramsey C, Buck CE, Burr GS, Edwards RL, Friedrich M, Grootes PM, Guilderson TP, Hajdas I, Heaton T, Hogg AG, Hughen KA, Kaiser KF, Kromer B, McCormac FG, Manning SW, Reimer RW, Richards DA, Southon JR, Talamo S, Turney CSM, van der Plicht J, Weyhenmeyer CE. 2009. IntCal09 and Marine09 radiocarbon age calibration curves, 0-50,000 years cal BP. Radiocarbon 51(4): 1111-50.

Stuiver M, Reimer PJ. 1993. Extended ${ }^{14} \mathrm{C}$ data base and revised CALIB $3.0{ }^{14} \mathrm{C}$ age calibration program. $R a$ diocarbon 35(1):215-30.

Stuiver M, Reimer PJ, Reimer RW. 2010. CALIB 6.0. Available at http:/calib.qub.ac.uk/calib. Accessed 12 February 2013. 